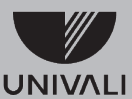

UNIVERSIDADE DO VALE DO ITAJAÍ

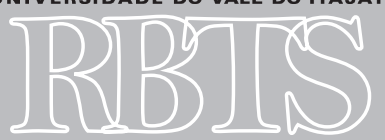

Revista Brasileira de Tecnologias Sociais

\section{O PORTAL DO CADERNO DE CIDADANIA COMO FERRAMENTA DE INCLUSÃO DIGITAL}

\section{THE CITIZENSHIP NOTEBOOK PORTAL AS A TOOL FOR DIGITAL INCLUSION}

\author{
Ana Cláudia Delfini Capistrano de Oliveira, Caroline Vieira Ruschel, Maria \\ de Lourdes Alves de Lima Zanatta, Elieser A. de Jesus, Elisangela M. DE \\ Miranda, Gabriel E.R. Couto, Luis Felipe Bortolozzo Zanatta, Rodrigo Lyra, \\ Rudimar S. Dazzi
}

RESUMO: Este artigo trata do desenvolvimento de um portal digital para divulgar as ações executadas pelo projeto de extensão da UNIVALI/Cejurps - Programa de Formação e Assessoria em Cidadania Infanto-juvenil - que possui o objetivo de ser uma ferramenta de inclusão digital para crianças e adolescentes. No portal existe um espaço para divulgar novidades, eventos, publicação de artigos, novas parcerias e um fórum para manter contato com os administradores e esclarecer dúvidas na interação com as crianças e os adolescentes. No trabalho de extensão foi utilizado para elaboração do portal e do jogo digital o método indutivo, já que cada etapa foi elaborada e trabalhada detalhadamente para obter-se o resultado final, qual seja, o sítio na internet, com a criação de um jogo digital. O método de procedimento foi o empírico, já que se obteve o auxílio de crianças e adolescentes para a elaboração de cada etapa, fortalecendo o papel da criança como ator social, na busca de um resultado mais efetivo e condizendo com a realidade das crianças.

Palavras-chave: Infância. Inclusão digital. Cidadania.

Abstract: This project focuses on the development of a digital portal to disseminate the actions of the extension project of UNIVALI/Cejurps - Programa de Formação e Assessoria em Cidadania Infantojuvenil ¿Program for Training and Advice in Citizenship for Children and Young People), which is intended as a tool for digital inclusion of children and young people. The portal has a space for disseminating news, events, articles, new partnerships, and a forum to keep in touch with administrators and clear up doubts in the interaction with children and adolescents. In the extension work, the inductive method was used to create a portal and a digital game, perfecting the details in each stage, to obtain the final result, i.e. the Internet website, with the creation of a digital game. The procedural method was empirical, as it included the help of children and adolescents in the elaboration of each stage, strengthening the role of the child as a social actor in the search for a more effective result that is more in keeping with the the children's reality

Keywords: Childhood. Digital inclusion. Citizenship. 
O Programa de Formação e Assessoria em Cidadania Infanto-juvenil é um projeto de extensão dos cursos de Direito e Relações Internacionais do CEJURPS/Universidade do Vale do Itajaí (UNIVALI), inserido na comunidade do Vale do Itajaí - SC e região desde 2004, tendo realizado inúmeras parcerias com entidades que atendem crianças e adolescentes em situação de vulnerabilidade social e digital da cidade de Itajaí e região. O programa tem como objetivo institucional desenvolver, dentro de uma linha metodológica que contempla a reflexão, formas de conscientização sobre cidadania, direitos e deveres da criança/adolescente e cidadania ambiental; e como objetivo específico produzir um jogo digital sobre cidadania e sustentabilidade socioambiental a partir do Caderno de Cidadania, material paradidático publicado em 2006 e doado para as entidades escolares parceiras do projeto. O programa também tem por objetivo a inclusão social, seja por meio dos conceitos trabalhados com crianças e adolescentes por meio do Caderno da Cidadania, seja por meio da inclusão digital desses atores. Além disso, o programa interage com seus parceiros por meio de oficinas pedagógicas estruturadas nos três módulos do Caderno de Cidadania, a saber:

No primeiro módulo, o objetivo é trabalhar o conceito de cidadania, mostrando que ser cidadão está além do conceito de voto. Ser cidadão implica aceitar direitos, mas também exercer deveres de auxílio ao Estado de Direito. Nesta fase, as crianças e os adolescentes percebem que eles também são atores sociais e que podem reivindicar, por exemplo, por melhorias no seu bairro, na sua escola, na sua cidade.

A cidadania não pode ter um caráter conclusivo, ela deve se constituir num processo de alta reflexividade que demande a crítica do próprio conceito. Ao se tratar da cidadania, é preciso refletir sobre tudo aquilo que nos impede da plena vivência, para não cair num debate retórico e politicamente correto. ${ }^{1}$

Módulo 1: Cidadania

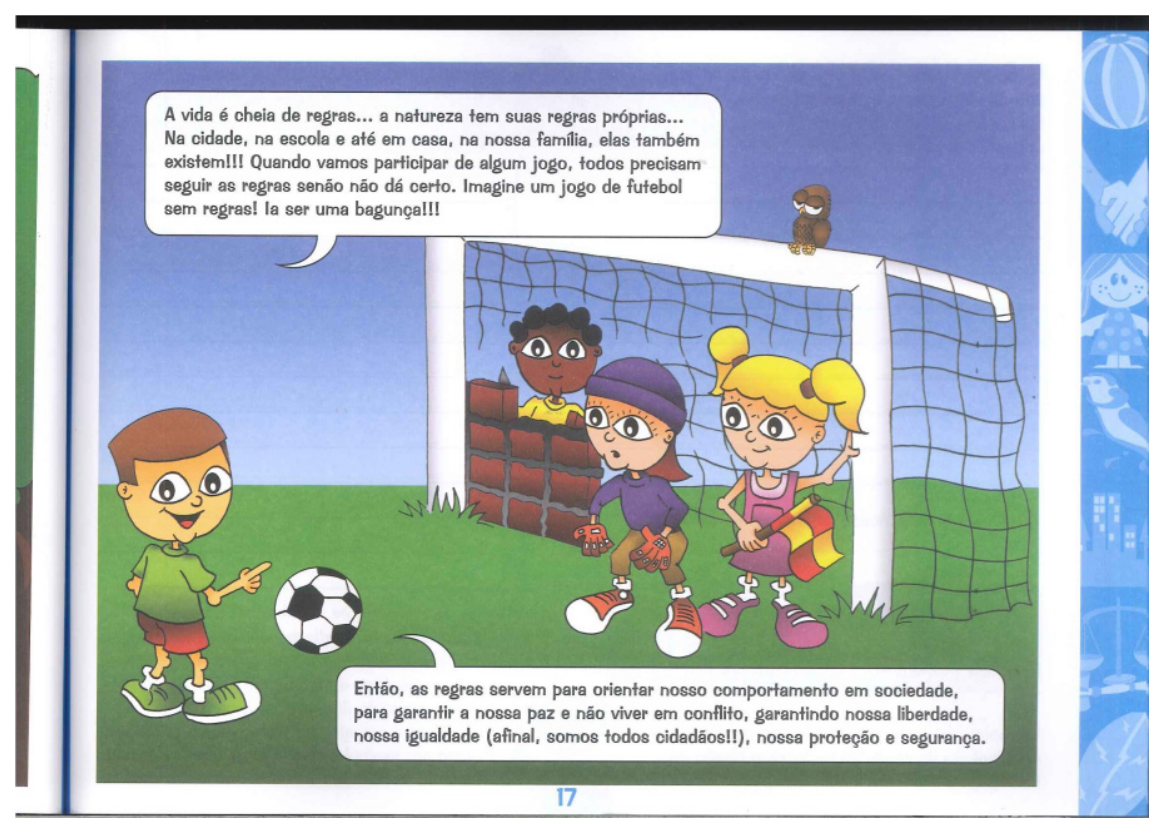

Figura 1: Este módulo trata de cidadania

1 OLIVEIRA. Ana Cláudia Delfini Capistrano (et al.). Diretrizes teóricas do Caderno da Cidadania. Florianópolis: ALESC, 2008, p. 14. 
O módulo 2 tem por objetivo tratar dos direitos e dos deveres da população infantojuvenil, prevista na Lei $n^{\circ}$ 8069/90, conhecida como Estatuto da Criança e do Adolescente. Neste tópico, trabalhou-se a importância do respeito aos direitos da população infanto-juvenil, mas também se enfatizou que, para se ter direitos, é preciso cumprir deveres.

Módulo 2: Estatuto da criança e do adolescente

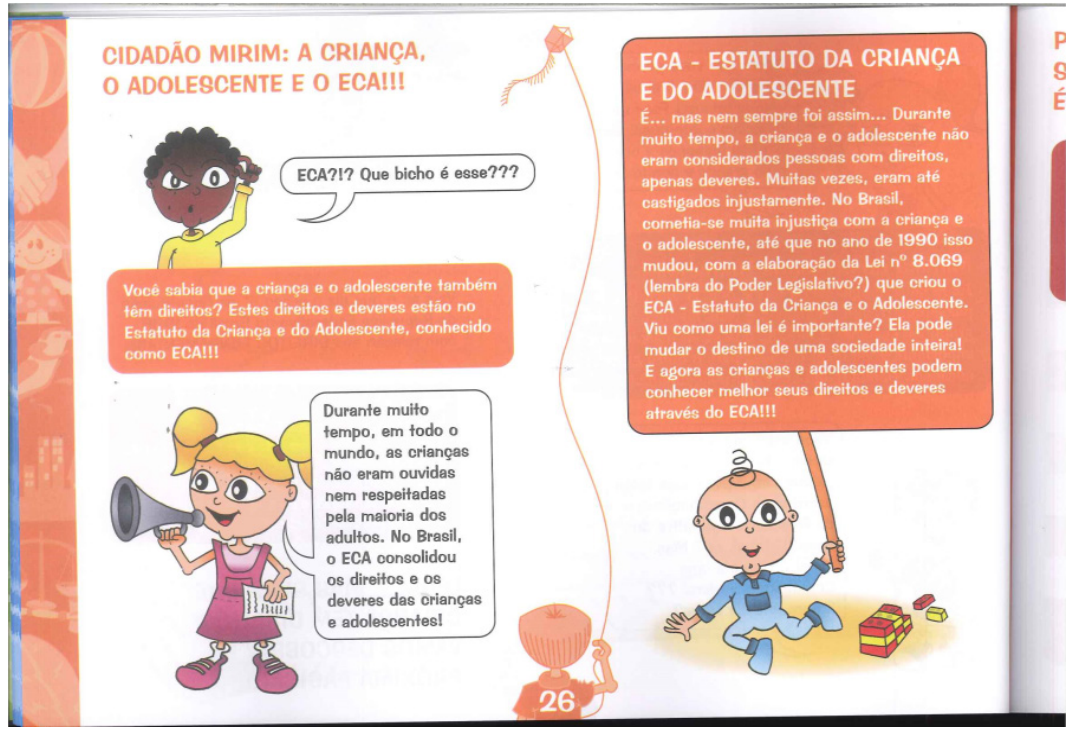

Figura 2: Módulo que trata do Estatuto da Criança e do Adolescente

O módulo 3 tem por objetivo sensibilizar a criança e o adolescente para aspectos socioambientais. Define o conceito de cidadania ambiental e trabalha conceitos legais relativos à Política Nacional do Meio Ambiente. Importante destacar que os direitos e os deveres socioambientais passam a ser parte integrante do conteúdo de cidadania, sendo reconhecidos e garantidos pela Constituição Brasileira de 1988.

Módulo 3: Cidadania socioambiental

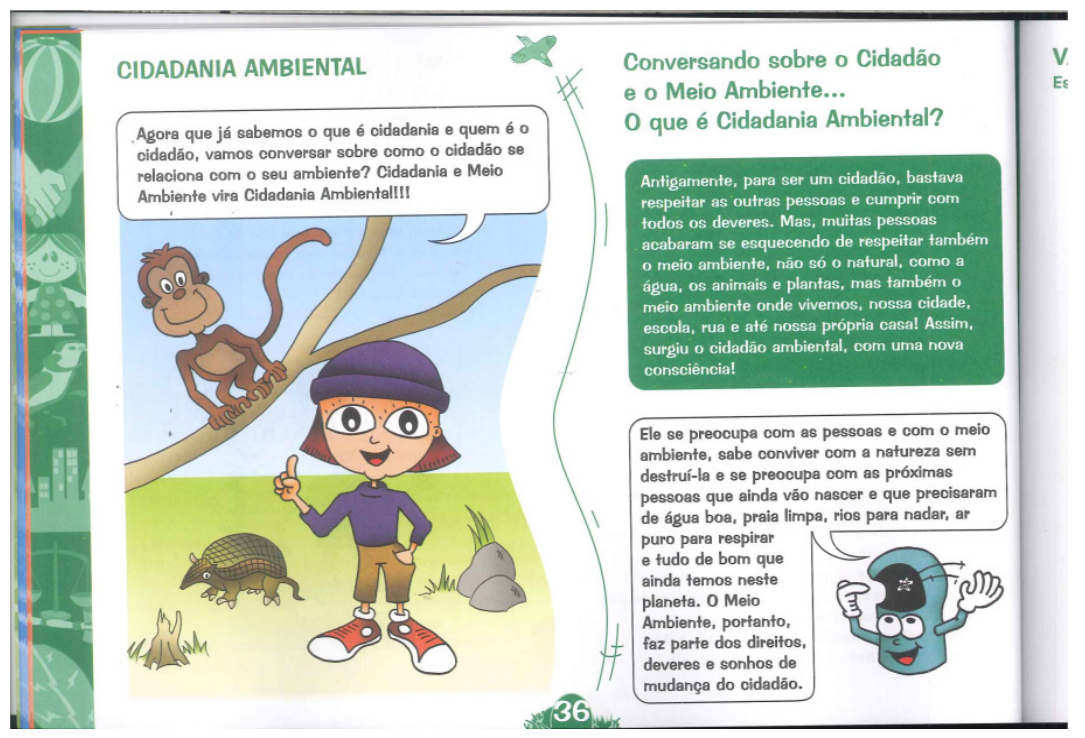

Figura 3: Módulo que trata de Cidadania Ambiental 
É neste contexto de educação, cidadania, inclusão social e meio ambiente que se desenvolveu uma parceria do projeto com o Laboratório de Inteligência Aplicada, com o objetivo de criar um portal on-line que possibilite a disponibilização do Caderno de Cidadania para escolas e para entidades do município e da região, a fim de promover a inclusão sociodigital. Aproveitando a possibilidade de um portal on-line, foram criados espaços para divulgar ações, novidades e informações sobre o Programa de Formação e Assessoria em Cidadania Infanto-juvenil. Assim, o programa utiliza suas inserções para desenvolver um jogo digital sobre consciência ambiental, tendo como base o feedback oportunizado pelas crianças e pelos adolescentes durante as oficinas realizadas, visando facilitar a aceitação dos conteúdos propostos ao público jovem.

A metodologia empregada utilizou-se da indução, ou seja, eram cumpridas etapas para a elaboração do portal e do jogo digital. Essas etapas tiveram o auxílio de crianças e adolescentes que, ao longo do processo, informavam a melhor forma de se fazer e desenvolver as ferramentas. O objetivo é chegar mais próximo da realidade social e ambiental desses cidadãos mirins. Os trabalhos de campo e os dados resultantes dessas atividades servem como base para este artigo, que trata sobre o desenvolvimento do Portal e elaboração do jogo digital, suas dificuldades e possibilidades do ponto de vista das crianças e dos adolescentes que participaram de sua criação e que utilizam a ferramenta nas atividades escolares e comunitárias.

\section{O PORTAL}

O portal é dividido em 9 sessões:

Blog: É uma sessão destinada a novidades sobre o programa, notícias sobre cidadania. Para ilustrar os tópicos, podem ser adicionados vídeos do youtube e imagens. Os visitantes podem compartilhar estas notícias pelo Twitter ou Facebook, e usuários podem fazer comentários no próprio tópico da notícia. A Figura 4 ilustra uma notícia no blog.

Na Home, a principal sessão do site, encontra-se uma apresentação do projeto, e logo abaixo as últimas três ações que estão sendo desenvolvidas, seguidas dos últimos três posts no blog.

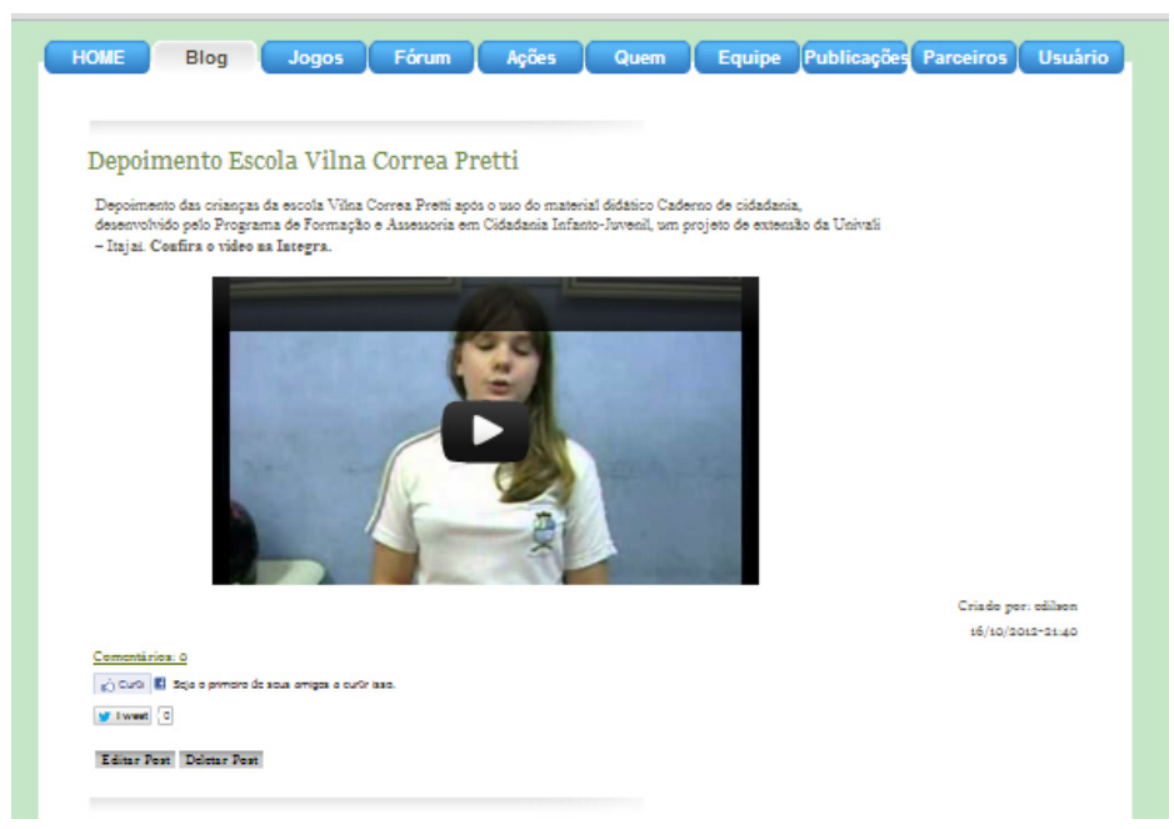

Figura 4: Exemplo de conteúdo do blog 
A sessão de jogos possui atualmente quatro jogos, os quais foram desenvolvidos no Laboratório de Inteligência Aplicada. O primeiro jogo chama $A$ trilha. Ele foi desenvolvido exclusivamente para ser disponibilizado no Portal de Cidadania. O jogo se trata de uma trilha virtual, na qual o jogador se depara com alguns desafios relacionados ao tema socioambiental, como retirar lixo do rio, realizar a coleta seletiva, entre outros, tudo isso enquanto percorre uma trilha procurando um animal típico da região, o lobo guará. Meu Planeta Minha Casa é um jogo que foi desenvolvido incialmente para ser jogado através de webcam, mas depois de vários testes, foi percebido que o jogo deveria ser manipulado por mouse teclado. O jogo se trata de vários problemas com o meio ambiente, os quais podem ser resolvidos de dentro de casa. Coleta Seletiva é um jogo em que o jogador deve controlar uma lixeira para evitar que lixos caiam no chão. OdontoGame é um jogo de tiro em primeira pessoa, em que o jogador deve destruir bactérias e restos de comida nos dentes; para isso, ele utiliza como arma uma pasta de dente, fio-dental e bombas de flúor.

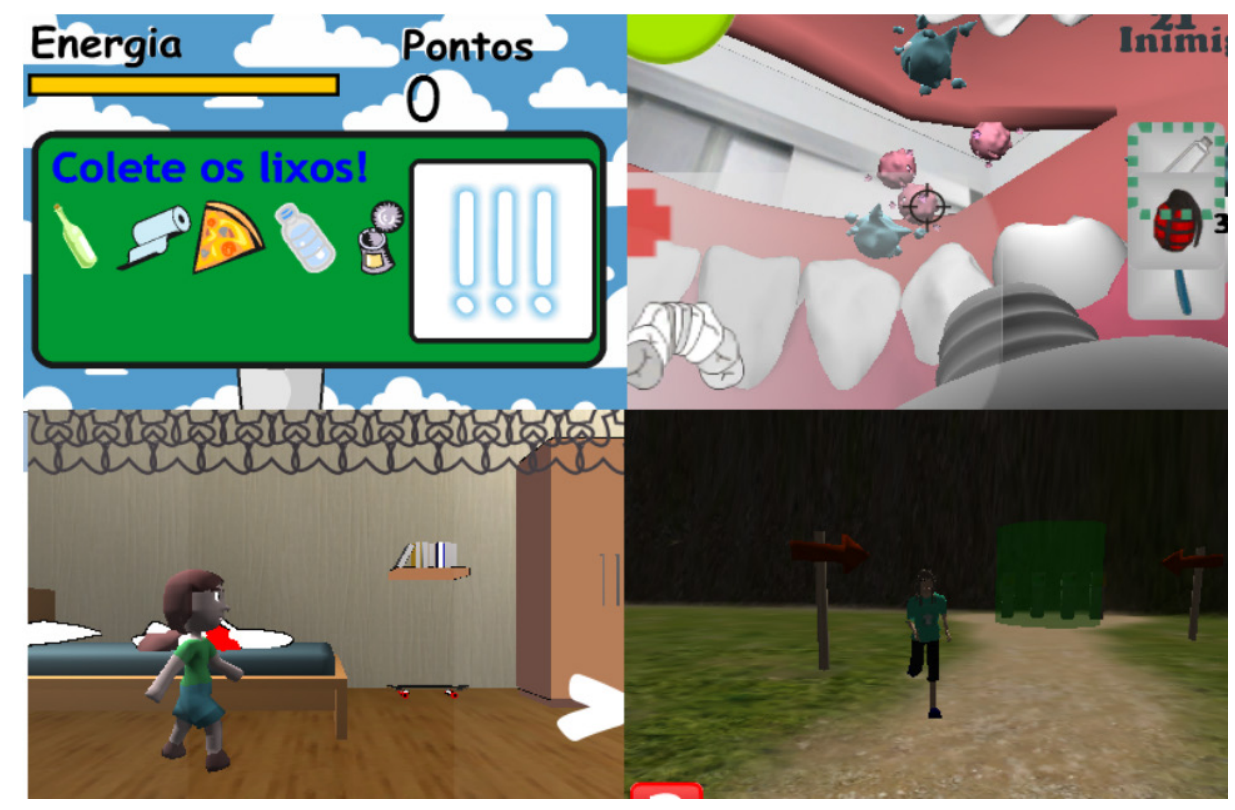

Figura 5: Os jogos Coleta Seletiva, OdontoGame, Meu Planeta Minha Casa e A Trilha

O fórum é a sessão em que usuários podem expressar sua opinião sobre atividades do projeto ou esclarecer dúvidas. Normalmente é utilizada após o trabalho nas escolas, estimulando o aluno a escrever e trabalhando a inclusão digital do mesmo. Qualquer pessoa cadastrada no site pode criar tópicos ou enviar comentários. Não são permitidos comentários e tópicos anônimos. A Figura 6 demonstra uma discussão no fórum, em que crianças expressam sua opinião sobre o jogo digital $A$ Trilha.

A sessão de Ações divulga todas as ações que o Programa de Formação e Assessoria em Cidadania Infanto-juvenil realizou. A sessão é organizada por data de início e possui uma descrição da ação, podendo possuir algumas fotos e links para o site representativo da ação. Na Figura 7, é possível visualizar a ação do primeiro Fórum sobre equidade de gênero.

A sessão Quem somos tem por objetivo fazer uma breve descrição do histórico, da metodologia e da missão do Programa de Formação e Assessoria em Cidadania Infantojuvenil. Apresenta a equipe com informações sobre todos os membros que trabalharam e trabalham no projeto. 


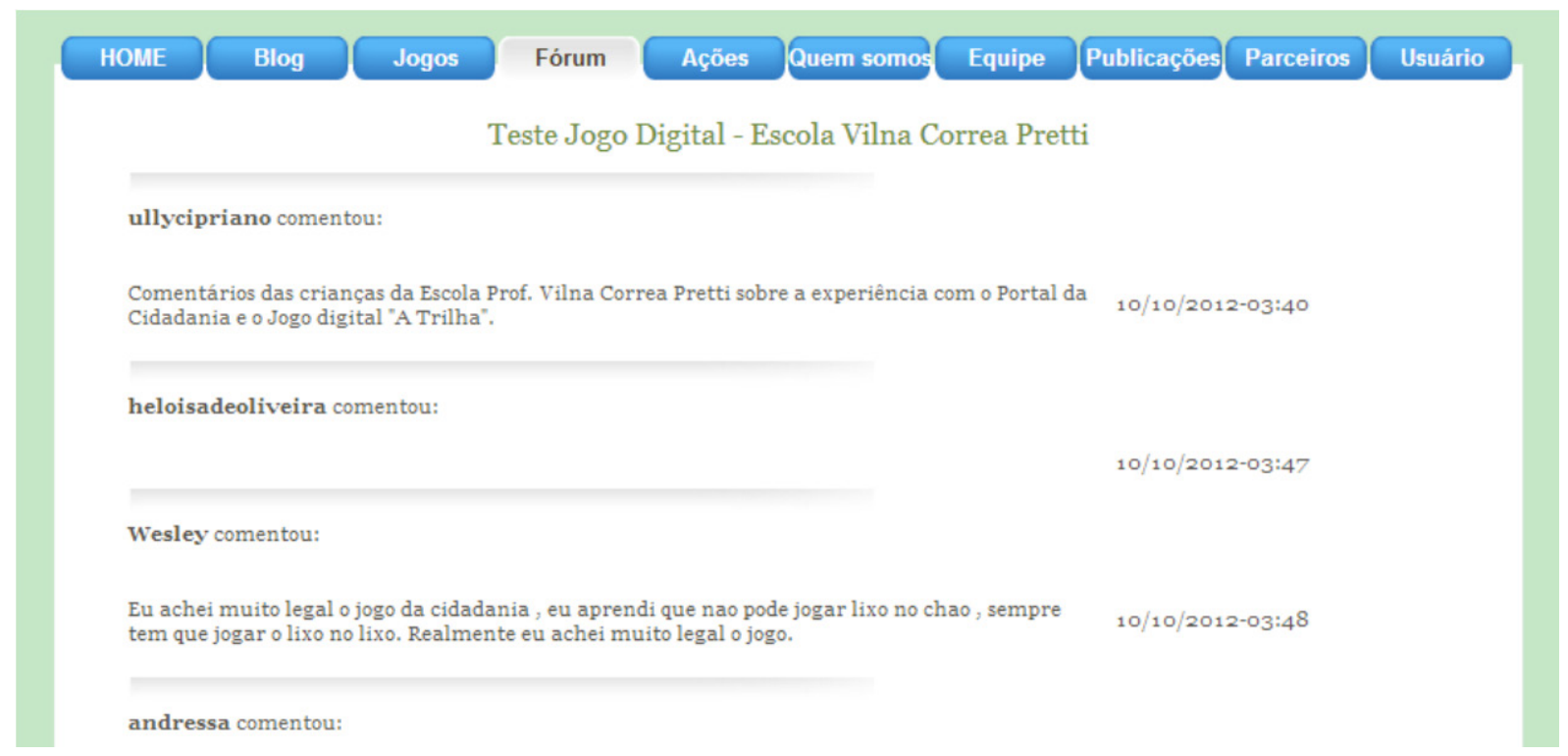

Figura 6: Discussão sobre o jogo $A$ Trilha no fórum

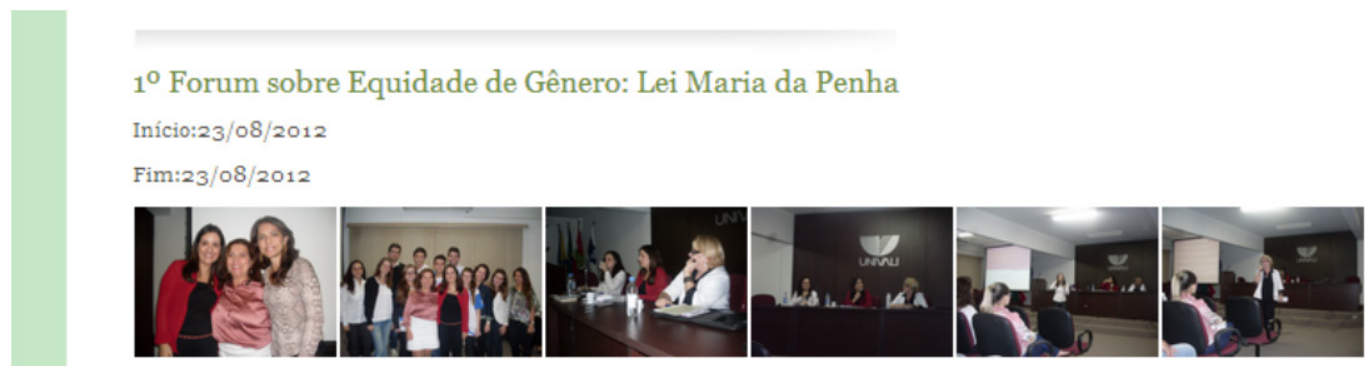

$01^{*}$ Fórum sobre equidade de gênero: Lei Maria da Penha, realizado no dia 23 de agosto de 2012 na Univali Itajaí, promoveu um novo debate sobre Gênero visando aumentar a discursão acerca do tema e da lei Maria da Penha (Lei 11.340), sancionada no ano de 2006, que foi promulgada tendo em vista os direitos dos cidadãos frente à violência domestica. $O$ evento contou com a participação da Delegada de Florianópolis Ana Silvia Ferrano e a Delegada de Itajaí Honorata Cachoeira Rodrigues. O evento foi realizado pelo Programa de Formação e Assessoria Infantojuvenil.

Acesse o site oficial aqui

Criado por: edilson

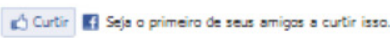

Tweot $\{0$

Figura 7: Ação do primeiro Fórum sobre equidade de gênero

A sessão Publicações se destina a divulgar as publicações de artigos dos membros dos projetos.

A sessão Parceiros possui uma descrição breve de cada um deles, possuindo um link para o site oficial, quando este existir.

Usuário: nesta sessão os visitantes podem se cadastrar, ou se possuírem uma conta, fazer o login. Feito o login, o usuário pode editar seus dados, alterar sua senha ou deletar a conta.

\section{Desenvolvimento}

O site foi desenvolvido na linguagem de programação PHP, utilizando o padrão de projeto de software MVC (Model-view-controller) e o sistema gerenciador de Banco de Dados MySQL. 
Todo o conteúdo do site é dinâmico, para separar o desenvolvedor da tarefa de alimentar o site com novos conteúdos, para isso foi criado um usuário administrador, que pode alterar dados das sessões Quem somos e Home, pois são as sessões que descrevem o projeto, logo é necessário muito cuidado com o que está escrito nestas sessões. O usuário administrador possui algumas opções a mais que os outros usuários, conforme ilustra a Figura 8.

Figura 8: Sessão usuário, quando este é administrador

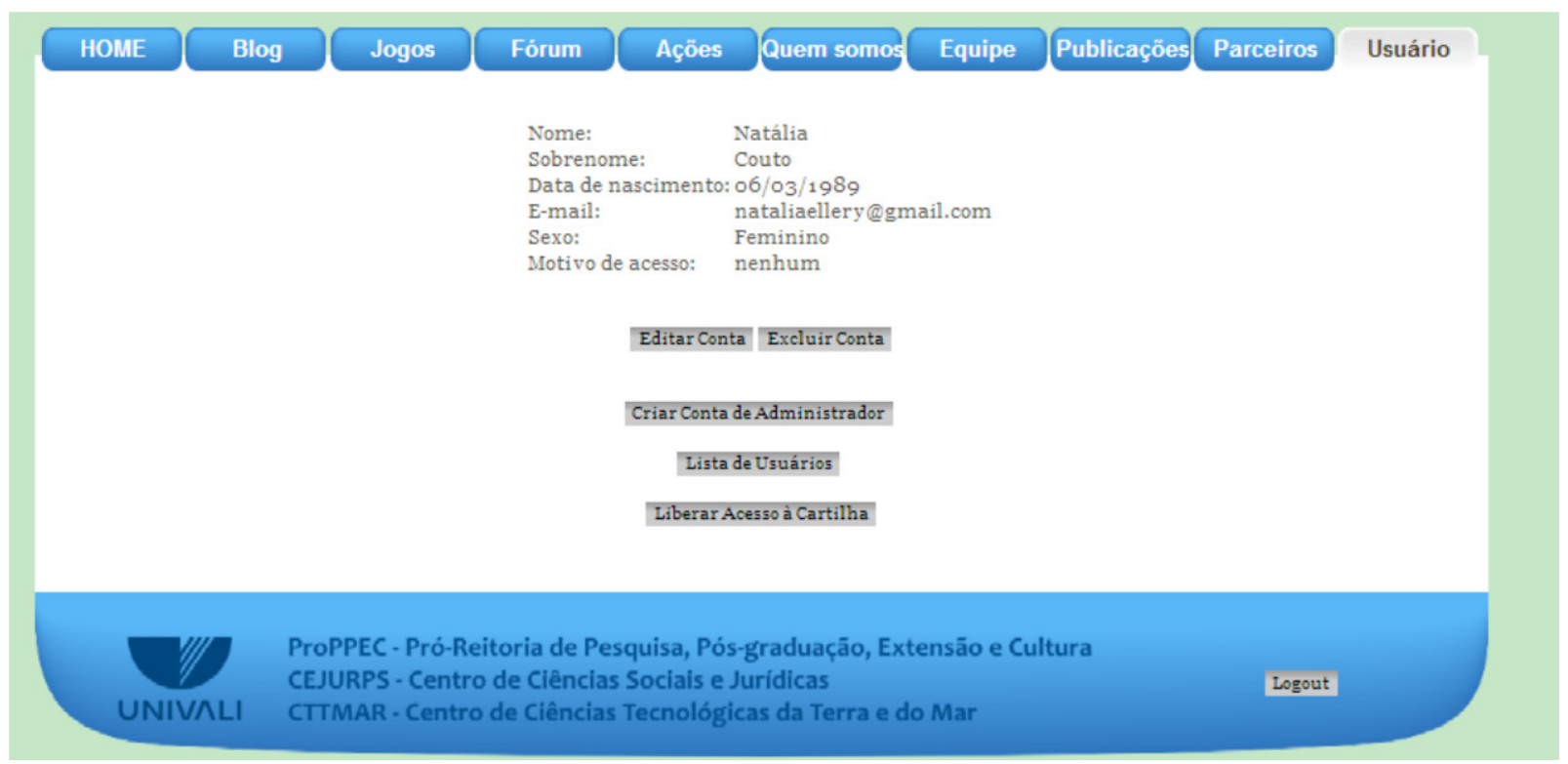

A opção "Criar Conta de Administrador" permite criar contas de usuários com diferentes privilégios. Os privilégios podem ser distribuídos conforme as sessões do portal, de acordo com a Figura 9.

Acessos

\begin{tabular}{|c|c|c|c|}
\hline & $\begin{array}{l}\text { Não pode inserir, } \\
\text { alterar ou excluir }\end{array}$ & $\begin{array}{c}\text { Inserir novos, } \\
\text { alterar e excluir } \\
\text { apenas os próprios }\end{array}$ & $\begin{array}{c}\text { Inserir novos, } \\
\text { alterar e excluir } \\
\text { todos } \\
\end{array}$ \\
\hline Blog* & $\bigcirc$ & $\bigcirc$ & $\bigcirc$ \\
\hline Fórum* & & $\bigcirc$ & ○ \\
\hline Equipe* & ( & ( & ( \\
\hline Publicações* & $\bigcirc$ & $\bigcirc$ & $\bigcirc$ \\
\hline Parceiros* & $\mathrm{O}$ & $\bigcirc$ & 0 \\
\hline Eventos* & ( & (1) & ( \\
\hline
\end{tabular}

Figura 9: Privilégios que um usuário pode obter quando criado pelo administrador

A primeira coluna indica que o usuário não poderá fazer alterações. A segunda coluna indica que o usuário possuirá os poderes de inserção, edição e exclusão apenas referente a conteúdos que ele próprio tenha enviado ao portal. A terceira coluna permite que o usuário possua privilégios de inserção, edição e exclusão referente a qualquer conteúdo da sessão, não importando qual usuário o tenha enviado.

A opção "Lista de Usuários" permite que o administrador possa verificar todos os usuários com contas ativas no portal, podendo também excluir qualquer conta, exceto sua própria. 
A opção "Liberar Acesso Cartilha” permite que o administrador possa liberar o acesso do caderno da cidadania para alguma conta de usuário, mas este acesso fica liberado por apenas certo tempo, que também é definido pelo administrador.

O portal também possui duas interfaces diferenciadas, a escolha desta interface é definida quando o usuário realiza o login. Um algoritmo faz a verificação da idade do usuário, e se ele possuir menos de 11 anos, os botões se transformam em peças de quebra-cabeça. A Figura 8 demonstra os botões normais, e a Figura 10 os botões em forma de quebra-cabeça.

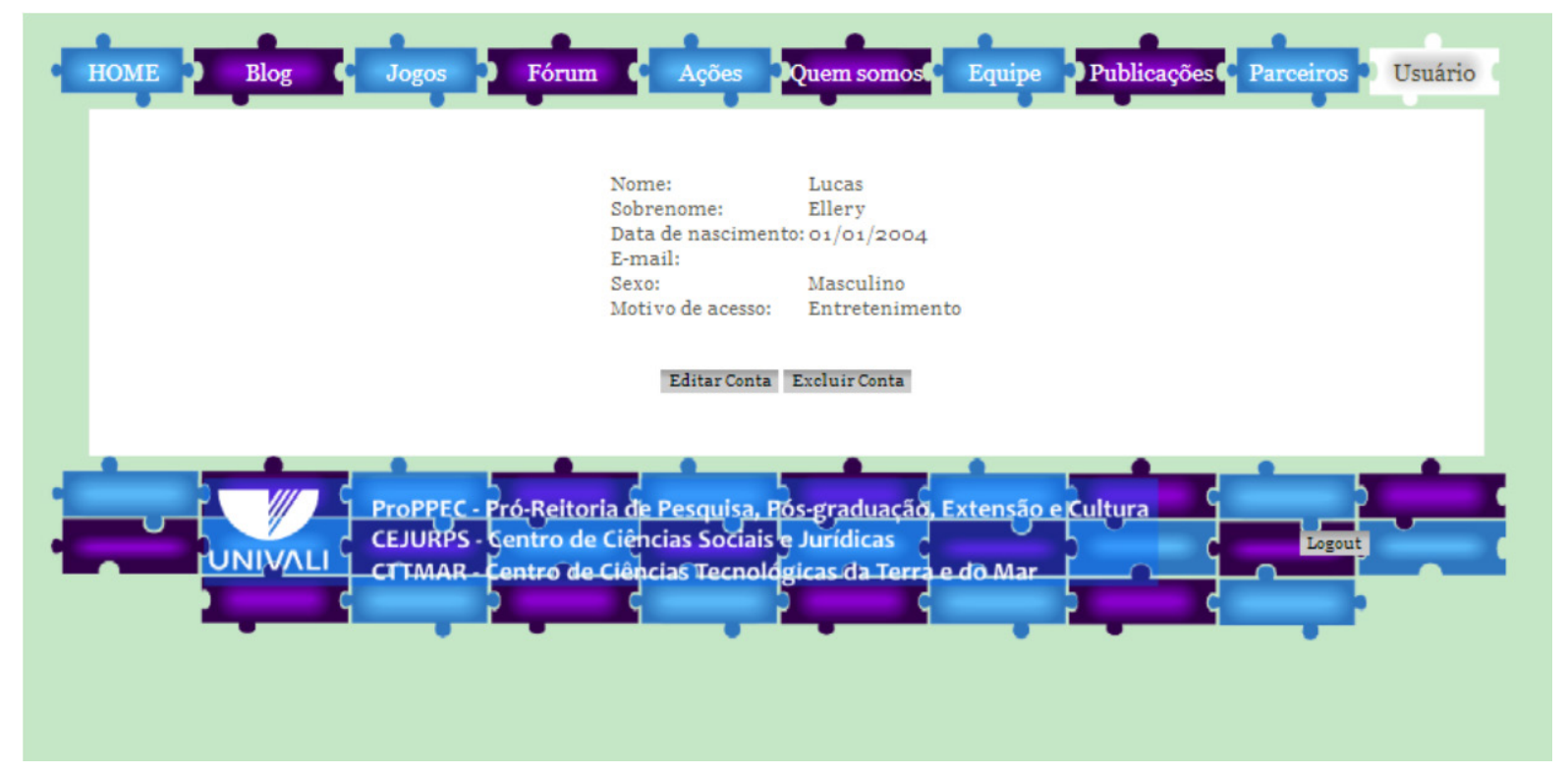

Figura 10: Interface do portal para usuários com menos de 11 anos

Testes

O Programa de Formação e Assessoria em Cidadania Infanto-juvenil tem como objetivo executar ações de formação e assessoria em cidadania infanto-juvenil sob o viés da defesa e da garantia dos Direitos Fundamentais, previstos na Constituição da República Federativa do Brasil de 1988. Graças às transformações sociais, políticas e jurídicas ocorridas na década de 1990, é possível observar a consagração dos direitos fundamentais da criança e do adolescente mediante a promulgação do Estatuto da Criança e do Adolescente (ECA), Lei n. 8.069/1990 e da criação do Conselho Nacional dos Direitos da Criança e do Adolescente, CONANDA, Lei n.8.242 de 1992. Todavia, nem sempre as conquistas jurídicas significam conquistas sociais, uma vez que a construção da cidadania plena impõe a tomada de consciência das populações sobre esses direitos, suas possibilidades e limites, ainda mais quando esta população se trata de crianças e adolescentes que se encontram em situação de vulnerabilidade social, portanto, à margem dos direitos. Neste sentido, a questão da eficácia social e jurídica impõe-se como foco de discussão no contexto do presente programa que se enquadra no que diz a Resolução n. 16/2010 do Ministério de Desenvolvimento Social e do Combate à Fome do Conselho Nacional de Assistência Social, a respeito de seu art. 1:

III - de defesa e garantia de direitos: aquelas que, de forma continuada, permanente e planejada, prestam serviços e executam programas ou projetos voltados 
prioritariamente para a defesa e efetivação dos direitos sócio assistenciais, construção de novos direitos, promoção da cidadania, enfrentamento das desigualdades sociais, articulação com órgãos públicos de defesa de direitos, dirigidos ao público da política de assistência social, nos termos da Lei n ${ }^{\circ} 8.742$, de 1993, e respeitadas às deliberações do CNAS de que tratam os incisos I e II do art. 18 daquela Lei, tais como: b) formação política-cidadã de grupos populares, nela incluindo capacitação de conselheiros/as e lideranças populares.

Neste contexto, segue, particularmente, agudo o problema da eficácia e da efetivação dos Direitos Fundamentais das crianças/adolescentes, de modo especial, o do acesso à educação por meio da inclusão digital como garantia do Direito à Educação previsto no cap. IV, título II, do ECA, em seu art. 53, que assegura o "pleno desenvolvimento de sua pessoa e o preparo para o exercício da cidadania." Sabe-se que na atual sociedade globalizada e informatizada que se vive hoje, o desenvolvimento da pessoa e seu eficiente exercício da cidadania social passam pela defesa e garantia da cidadania digital, como diz o sociólogo Pedro Demo:

(...) a inclusão digital está cada vez mais no centro da inclusão social. (...) Interessanos aqui a discriminação digital contra imensos segmentos sociais pobres, situação em geral agravada pela má qualidade da escola pública. (...). Sobre este pano de fundo, emergem pelo menos dois grandes horizontes: enfrentar o atraso tecnológico, para não ficar para trás definitivamente e enfrentar a precariedade da escola pública, para não permitir que a população seja incluída na margem. (DEMO, 2003, p.15).

Os jogos digitais são usados por milhões de pessoas no mundo como forma de entretenimento, conscientização, educação socioambiental, com temáticas da fauna e da flora, dentre outras, tornando-se uma ferramenta útil para se aprender brincando sobre qualquer assunto. Porém, a elaboração de um jogo passa pela superação de algumas dificuldades, por exemplo: estabelecer um padrão de “jogabilidade”; elaborar um conteúdo de fácil absorção pelos usuários para o desenvolvimento de um senso crítico dos temas ambientais; favorecer situações de interação entre os usuários e criar uma linguagem atrativa às diversas faixas etárias (crianças, adolescentes, adultos e idosos), uma vez que seus interesses são diferentes. Uma das alternativas encontradas para contornar essa questão foi promover a interação das atividades por meio de um grupo heterogêneo de crianças (RUSCHEL, 2012).

Desde o início do ano de 2011, o Programa de Formação em Cidadania Infanto-juvenil enfatiza diálogos pertinentes às problemáticas ambientais e ao meio ambiente por meio das experiências e das respostas obtidas com as crianças e adolescentes que participam do projeto. A partir destas experiências, as crianças e os adolescentes puderam ajudar na elaboração de ideias e caminhos para a criação do Portal e do jogo $A$ Trilha.

Durante as oficinas pedagógicas, foram realizados testes com 30 crianças e adolescentes de vários grupos sociais, etários, étnicos e de gênero para obter a sua participação na montagem do site e do jogo. As crianças criaram um cadastro no portal, testaram o jogo digital $A$ Trilha, navegaram um pouco pelas sessões do portal e, por fim, utilizaram o "Fórum" para dar a sua opinião sobre o jogo e o portal. Durante os testes foi possível perceber que algumas crianças tiveram bastante dificuldade em criar a conta, principalmente no campo de escolher um nome para o usuário, colocando espaço em branco entre as palavras. Também havia crianças que já tinham bastante experiência com o facebook, fazendo com que estas tivessem mais facilidade na criação da conta. 
A metodologia utilizada nas oficinas permitiu captar elementos propícios à construção do jogo, buscando a sensibilização dos participantes a partir de técnicas como "A teia da vida”, a "Árvore dos Sonhos" e o "Muro das Lamentações". Nestas oficinas, que ocorrem quinzenalmente, aplicase também o jogo do Tabuleiro de Mesa como técnica para pensar o jogo digital, oportunizando as crianças uma participação efetiva na criação das situações problemas do mesmo. O tabuleiro reflete os problemas socioambientais e sua conscientização, servindo de parâmetro para o jogo digital; espera-se com isso maior integração no processo de criação do jogo e não somente mera atração. Ao final do jogo do Tabuleiro, as crianças são divididas em dois grupos e elas montam frases e/ ou desenhos que refletem sua conscientização ambiental com aspectos positivos e negativos de sua relação e vivência (RUSCHEL, 2012).

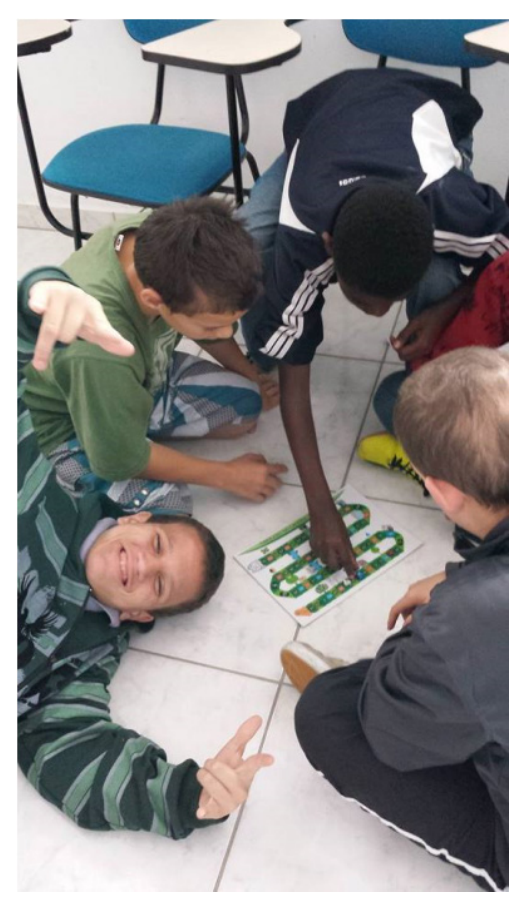

Figura 11: Acervo das crianças do Parque Dom Bosco

Atualmente, os membros do Programa de Formação e Assessoria em Cidadania Infantojuvenil estão alimentando o portal com conteúdos referentes a novidades, publicações, eventos

2 Para tal atividade, o coordenador utiliza um rolo de barbante e lança uma pergunta sobre o que é indispensável ou fundamental à vida do participante. Quem inicia responde a pergunta e, segurando uma ponta do barbante, lança outra ponta para outra pessoa responder a mesma pergunta e assim sucessivamente, formando uma rede entre os participantes ao final. Após todas as respostas, o coordenador da atividade promove uma reflexão sobre essa teia baseada na ideia de que se um dos lados se rompe - utilizando uma tesoura, ele corta alguma parte dessa teia para demonstrar o rompimento -, todos os outros serão prejudicados com isso. Geralmente essa oficina é realizada com os professores e multiplicadores no início das capacitações.

3 Nesta técnica os participantes descrevem em uma folha de papel, que pode ser no formato de uma folha de árvore, seus quatro principais sonhos para um determinado local, seja a sua rua, comunidade, escola ou bairro. Após isso, colam na árvore desenhada em um papel grande providenciada pelo coordenador e, assim, após cada participante da oficina colar a sua folha em determinado local da árvore, ela vai se constituindo. Essa técnica teve sua origem na ECO-92, quando pessoas do mundo todo escreveram seus sonhos de futuro em papéis em forma de folhas. Essas folhas foram penduradas nos galhos de uma árvore gigante, que foi instalada na praia do Flamengo, no Rio de Janeiro, como símbolo de um futuro mais feliz para todos. Esses sonhos, escritos, desenhados, pintados etc., se transformam na árvore dos sonhos, montada coletivamente.

4 A oficina remete ao monumento que fica na cidade de Jerusalém. Os visitantes do local colocam mensagens entre as pedras do muro com seus sonhos e lamentações. Assim, são recortados pedaços de papel em forma e cor de pequenos tijolos, nos quais cada participante escreve suas lamentações. No caso, a atividade é direcionada às questões ambientais, assim as lamentações podem se referir ao ar, à agua, a terra, ao fogo, etc. Ao final, cada participante cola seu tijolo de papel em uma grande cartolina, formando o muro. 
na área de cidadania. O Caderno de Cidadania pode ser encontrado na sessão de publicações, mas apenas usuários autorizados podem acessá-lo. Para conseguir a autorização, o visitante deve solicitar aos membros do projeto a autorização.

Existe a proposta da criação de um programa de capacitação on-line, que, ao término da capacitação, o capacitado possuirá acesso total ao caderno de cidadania. A proposta da capacitação é necessária para auxiliar as pessoas a utilizarem corretamente o caderno de cidadania. Além do programa de capacitação on-line, existe também a ideia de criar uma revista na mesma sessão de publicações do portal.

\section{ConClusões}

O jogo digital possui o objetivo de proporcionar a inclusão social e digital de seus usuários, bem como a conscientização socioambiental das crianças e dos adolescentes. Os depoimentos das crianças no fórum do site mostram que a percepção delas sobre o jogo foi muito positiva. As discussões no fórum mostraram que o ponto mais difícil no jogo é a poluição nos rios, uma vez que, se pegar peixes quando está “caçando” lixo, o nível de poluição do rio volta a subir, deixando o jogador mais longe de alcançar seu objetivo.

As crianças que auxiliaram na construção do jogo acertaram ao escolher o lobo guará como objetivo final da trilha. São inúmeros comentários favoráveis ao animal, como, por exemplo: "Eu aprendi o quanto é bom ter um meio ambiente limpo, o quanto seria triste se animais como o lobo guara que foi uns dos objetivos do jogo fosse extinto.”

Outro ponto que fica marcado nos comentários de quem joga é a reciclagem, muitos destacam a importância de reciclar e se comprometem a prestar mais atenção quanto à reciclagem em suas casas. Observaram-se também alguns comentários, sugerindo que sejm feitos mais jogos como esse, pois, segundo as crianças, é muito mais fácil prestar atenção em algo que os mantém entretidos: "Gostei muito dos jogos, poderiam criar mais, pois tem poucos. e ajuda muito as crianças como se comportar na sociedade entre pessoas de diferentes classes sociais e etnias. Etc...”

O portal também permitiu que o aprendizado em cidadania fosse estendido por meio de jogos educacionais, permitindo que os jogos sejam acessados de qualquer lugar que possua um computador com internet. Ele contribuiu também para a inclusão digital de crianças e jovens nas escolas parceiras do projeto.

Este projeto também comprovou que trabalhos que envolvem parcerias de áreas e disciplinas diferentes podem gerar bons resultados, fazendo com que cada área contribua com o melhor de si, neste caso a área de Direito, contribuindo com o conhecimento sobre a cidadania e a área de tecnologia, construindo uma ferramenta na qual este conhecimento possa ser divulgado e acessado por todos.

\section{REFERÊNCIAS}

ALMEIDA, Fernando. O bom negócio da sustentabilidade. Rio de Janeiro: Nova Fronteira, 2002.

CARvalHO, André. Novas janelas para o mundo. Canal RH, n. 69, mar./abr. 2009. Disponível em: http://www.canalrh.com.br/revistadig/home.aspx?materia=246\&busca=. Acesso em: 7 set. 2011.

CAVEDOn, Fernanda de Salles. In: Diretrizes teóricas do Caderno de Cidadania: reflexões sobre 
54 - RBTS - v.1, n.2, 2014

cidadania e direitos humanos, estatuto da criança e do adolescente e cidadania ambiental. Florianópolis: ALESC, 2008.

DECLARAÇÃO UNIVERSAL DOS DIREITOS HUMANOS, 1948. Disponível em: <http://portal. mj.gov.br/sedh/ct/legis_intern/ddh_bib_inter_universal.htm>. Acesso em: 7 set. 2011.

DEMO, Pedro. Cidadania tutelada e cidadania assistida. Campinas: Autores Associados, 1995.

DEMO, Pedro. Sociologia, uma introdução crítica. 2. ed. São Paulo: Atlas, 1987.

FREIRE, Paulo. Pedagogia da autonomia: saberes necessários à prática educativa. 37. ed. Rio de Janeiro: Paz e Terra, 2008.

MELLO, Elisângela de Fátima Fernandes de; TEIXEIRA, Adriano Canabarro. Um processo de inclusão digital na hipermodernidade. In: MARCON, Karina; TEIXEIRA, Adriano Canabarro (Org.). Inclusão digital: experiências, desafios e perspectivas. Passo Fundo: Universidade de Passo Fundo, 2009.

MORIN, Edgar. Os sete saberes necessários à educação do futuro. 2. ed. São Paulo: Cortez, 2000.

OLIVEIRA, Ana Cláudia Capistrano de et al. Direitos humanos e cidadania infanto-juvenil. In: BITENCOURT, Lisiane Tuon G.; BÚRIGO, Liege Inocêncio; GARCIA, Berenice Rocha Zabbot. Direitos humanos: infância e adolescência - a contribuição da extensão universitária. Joinville: Editora Univille, 2008.

PADOLFI, Dulce Chaves et al. Cidadania, justiça e violência. Rio de Janeiro: Fundação Getúlio Vargas, 1999.

PELLANDA, Nize Maria Campos. O sentido profundo da solidariedade. In: PELLANDA, Nize Maria Campos; SCHLÜNZEN, Eliza Tomoe Moriya; JUNIOR, Klaus Schlünzen (Org.). Inclusão digital. Rio de Janeiro: DP\&A, 2005.

PIOLLI, Alessandro. Acesso a informação promove inclusão social. Cultura Científica, 10 jul. 2003. Disponível em: <http://www.comciencia.br/reportagens/cultura/cultura06.shtml>. Acesso em: 7 set. 2011.

RADTKE, Márcia Leão; SANTOS, Bettina Steren dos Santos. Inclusão digital: reflexões sobre a formação docente. In: PELLANDA, Nize Maria Campos; SCHLÜNZEN, Eliza Tomoe Moriya; JUNIOR, Klaus Schlünzen (Org.). Inclusão digital. Rio de Janeiro: DP\&A, 2005.

RUSCHEL, C. V.; SILVA, B.; FIlASTRO, F.; ZANATTA, L. F.; OLIVEIRA, J. P. C.; ZANATTA, M. L. A. L.; CIPRIANO, U. Formação e assessoria infanto-juvenil: os jogos digitais como instrumentos de educação sócio ambiental. As metodologias de intervenções em programas e projetos de extensão. v.1, p.7 - 159, 2012.

SILVEIRA, Sergio Amadeu. Inclusão digital reduz exclusão social? A Rede, maio 2009. Disponível em: <http://www.arede.inf.br/inclusao/component/content/article/112-destaques/1643-fotografite>. Acesso em: 7 set. 2011. 